\title{
NITROGEN MONOXIDE AS A FACTOR OF ACTIVATION OF THE PROOXIDANT SYSTEM ON THE BACKGROUND OF SUBSIDIES OF HIGH CONCENTRATIONS OF OXYGEN IN NEWBORNS WITH RESPIRATORY DISTRESS
}

\author{
Oleksandr Buriak ${ }^{1}$, Nataliia Pavliukovych ${ }^{2}$, Oleksandr Pavliukovych ${ }^{3}$, \\ Nataliia Popeliuk ${ }^{4}$, Tamara Kopchuk ${ }^{5}$
}

\begin{abstract}
Data about the peculiarities of metabolism of endogenous NO in modern literature are quite controversial, especially in newborns with respiratory distress who need artificial lung ventilation. Investigating of the peculiarities of peroxidation processes on the background of excessive accumulation of nitrogen monoxide metabolites due to the inhalation of different concentrations of oxygen among newborns with severe respiratory insufficiency.

84 newborns who were admitted to the department of intensive care of newborns were under investigation. They were randomized into groups according to their oxygen saturation index of the inhaled mixture. The exhaled breath condensate was tested for nitrogen monoxide metabolites, malonic aldehyde, aldehyde and ketone derivatives of the 2,4-dinitrophenyl hydrazine of a neutral and basic (aggregates of protein molecules) nature.

Obtained results indicated that nitrogen monoxide (active oxidant) directly affects the increase of activity of processes of proteins and lipids peroxidation by increasing the total oxidation potential. Excessive endogenous NO formation under the conditions of subsidizing of high concentrations of oxygen leads to an increase in excessive formation of nitrogen monoxide and is a risk factor for the initiation of oxidative stress processes.

Thus, nitrogen monoxide is one of the factors of activation of free radical oxidation at the level of alveolar-capillary space among newborns with respiratory distress. In intensive care for newborns with severe respiratory failure, the use of excessive oxygen concentrations should be avoided, as on the background of increased endogenous NO formation, there is a risk factor for the toxic effect of oxygen on the biological structures due to the increased formation of active forms of oxygen with the development of oxidative stress.
\end{abstract}

UDC Classification: 616.2; DOI: http://dx.doi.org/10.12955/cbup.v6.1264

Keywords: nitrogen monoxide, respiratory distress, newborns, exhaled breath condensate

Introduction. Nitrogen monoxide is one of the most important regulators of certain physiological and biochemical processes in the body. It is continuously produced enzymatically in the organism and is a potentially toxic molecule. According to Zubrihina et al. (2007) the high reactivity of nitrogen monoxide (NO) is due to the presence of an unpaired electron in its orbit $(\mathrm{N}=\mathrm{O})$. The $\mathrm{NO}$ radical can react in biological systems with oxygen, superoxide anion radical and other ions.

With excess accumulation during illness, nitrogen monoxide has a pronounced constrictive effect on the smooth muscles of the bronchial tree. It is described by Junichi et al. (2005) that inactivation of antioxidant enzymes occurs, which is followed by even more sharply increased processes of peroxide and free radical oxidation, resulting in increased permeability of the vessel wall, its inflammatory edema and the increased production of pro-inflammatory biologically active substances. It is supposed by Frye (2005) that hyperproduction of these bioregulatory molecules contributes to the development of parenchymal respiratory failure, thereby violating pulmonary hemodynamics and increasing vascular permeability, leading to total pulmonary edema.

Yaschenko and Buriak $(2010,2011)$ found out that in the conditions of oxidative stress, NO interacts with the superoxide anion $\left(\mathrm{O}_{2}^{-}\right)$to form peroxynitrite, which leads to the formation of a hydroxy radical $(\mathrm{OH}-)$, which in a way explains the cytotoxicity of NO. Peroxynitrite, in turn, is a prominent oxidant that can damage the alveolar epithelium and pulmonary surfactant.

However, data about the state of metabolism of endogenous NO in modern literature are quite controversial. The mechanisms for the transformation of nitrogen monoxide from a protective to a damaging agent remain unidentified.

Aim: to investigate the peculiarities of peroxidation processes on the background of excessive accumulation of NO metabolites due to the inhalation of different concentrations of oxygen among newborns with severe respiratory insufficiency.

\footnotetext{
${ }^{1}$ Bukovinian State Medical University, Ukraine, buriakoleksandr1983@gmail.com

${ }^{2}$ Bukovinian State Medical University, Ukraine, natasha.pavlyukovich@gmail.com

${ }^{3}$ Bukovinian State Medical University, Ukraine, olexandr.pavlyukovich@gmail.com

${ }^{4}$ Bukovinian State Medical University, Ukraine, popeliuk@yandex.ru

${ }^{5}$ Bukovinian State Medical University, Ukraine, pharmacology@bsmu.edu.ua
} 
Material and Methods of Investigation. 84 newborns who were admitted to the department of intensive care of newborns were investigated. The patients were randomized in accordance with the following criteria: 1) clinical signs of respiratory distress; 2) the period of gestation is not less than 3840 weeks; 3 ) the need for artificial ventilation of the lungs (mechanical ventilation); 4) the absence of birth defects.

Clinical respiratory insufficiency in newborns manifested through the clinical symptoms of severe hypoxemia and hypoxia, hemodynamic disorders, which required the prescription of oxygen therapy and vasoactive drugs (Table 1).

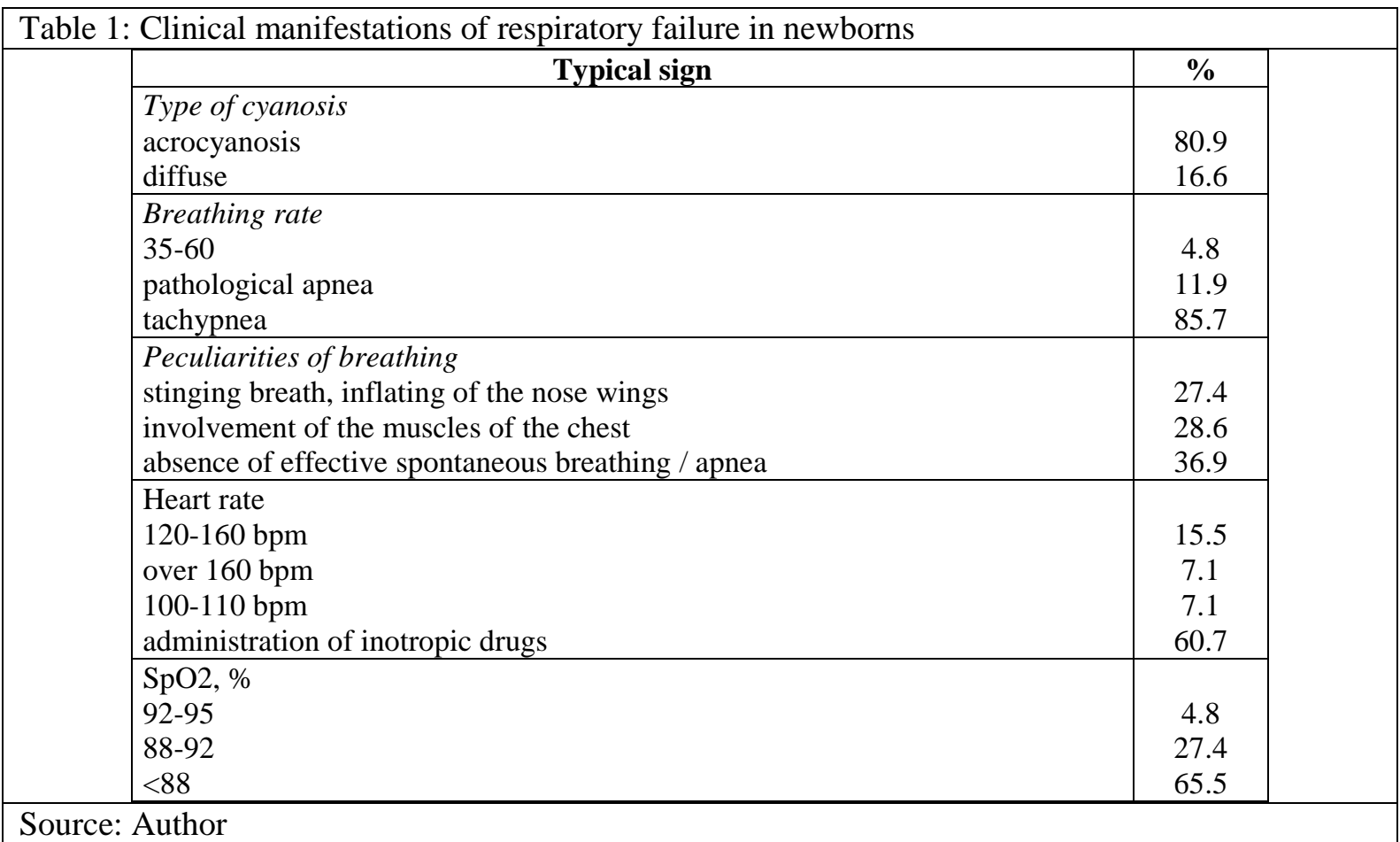

Chest X-rays that confirmed signs of interstitial and alveolar edema was performed for all newborns.

To find out the intensity of the peculiarities of peroxidation processes on the background of excessive formation of nitrogen monoxide metabolites due to the application of various concentrations of oxygen during the intensive care of newborns with respiratory distress, patients were randomized into 3 groups. I group -23 newborns, among which during artificial lung ventilation the oxygen saturation index $\left(\mathrm{FiO}_{2}\right)$ was above 0.5 ; II group - 44 newborn, who received respiratory support in the conditions of $\mathrm{FiO}_{2}$ 0.3-0.5; III group - 17 newborns, among which during artificial lung ventilation the oxygen saturation index of the mixture, which was inhaled by the child was less than 0.3 .

To examine the nitrosative status and the activity of peroxidation processes in the lungs, the exhaled breath condensate (EBC) was tested. Pulmonary extracts were collected from the respiratory system of the apparatus of mechanical ventilation (on exhalation). The content of nitrogen monoxide metabolites in pulmonary expirates was determined by photometry using Grays' reagent (Flanagan et al., 1997). Peroxide lipid oxidation was defined by the detection of malonic aldehyde. The intensity of the oxidative modification of proteins was determined by the content of aldehyde and ketone derivatives of the 2,4-dinitrophenyl hydrazine of a neutral and alkali (aggregates of protein molecules) nature.

\section{Results of the Investigation.}

The investigation of the nitrosative status in newborns with severe respiratory disorders found out that in the newborns of I and II groups, the content of NO metabolites in EBC was statistically significantly higher than that of the children of the III group (Figure 1). 


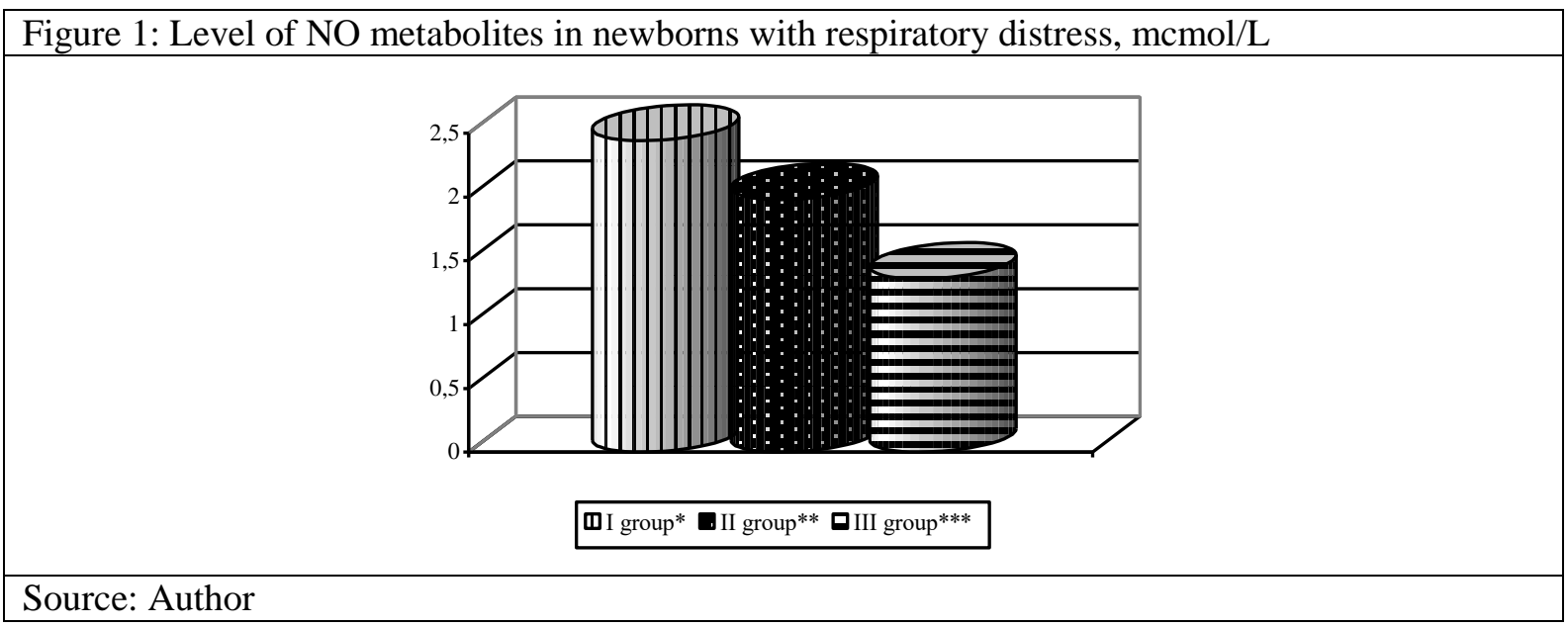

\begin{tabular}{|c|c|c|c|c|c|c|}
\hline Figure & $\beta$-coefficient & $\begin{array}{c}\text { Standard } \\
\text { error } \beta\end{array}$ & B & $\begin{array}{c}\text { Standard } \\
\text { error B }\end{array}$ & T-statistics & $\begin{array}{c}\text { Significance } \\
\text { Level }\end{array}$ \\
\hline & \multicolumn{6}{|c|}{ I group } \\
\hline $\mathrm{NO}$ & 0.653654 & 0.137243 & 0.049975 & 0.010493 & $\mathbf{4 . 7 6 2 7 5 7}$ & 0.000084 \\
\hline Malonic aldehyde & 0.559002 & 0.066117 & 0.024435 & 0.00289 & 8.45479 & 0.013702 \\
\hline Dyne conjugates & 0.403409 & 0.073563 & 0.096978 & 0.017684 & 5.483857 & 0.031681 \\
\hline $\mathrm{FiO}_{2}$ & -0.44234 & $\mathbf{0 . 0 9 5 8 3 4}$ & -1.48818 & 0.322419 & -4.61568 & 0.043873 \\
\hline \multicolumn{7}{|c|}{ II group } \\
\hline $\mathrm{NO}$ & 0.589521 & 0.09719 & 0.963211 & 0.158798 & 6.065657 & 0.02612 \\
\hline Malonic aldehyde & 0.245162 & 0.142304 & 0.586039 & 0.340166 & 1.722804 & 0.098345208 \\
\hline Dyne conjugates & -0.64055 & 0.177986 & -0.09424 & 0.026187 & -3.59888 & 0.069281 \\
\hline $\mathrm{FiO}_{2}$ & -0.2974 & 0.137262 & -0.10538 & 0.048638 & -2.16667 & 0.040865562 \\
\hline \multicolumn{7}{|c|}{ III group } \\
\hline $\mathrm{NO}$ & -0.15225 & 0.136907 & -0.2331 & 0.209607 & -1.1121 & 0.294919 \\
\hline Malonic aldehyde & 0.391621 & 0.128091 & 0.671548 & 0.219649 & 3.057375 & 0.013629 \\
\hline Dyne conjugates & -0.19893 & 0.107188 & -0.06652 & 0.035841 & -1.85592 & 0.096438 \\
\hline $\mathrm{FiO}_{2}$ & 0.164956 & 0.14032 & 10.96898 & 9.330773 & 1.17557 & 0.269927 \\
\hline
\end{tabular}

Source: Author

We tried to find out the regularities of the influence of metabolites of $\mathrm{NO}$ on the processes of peroxidation in newborns on the background of donation of high concentrations of oxygen during mechanical ventilation. This is due to the fact that both the excessive production of NO metabolites and the subsidization of high concentrations of oxygen lead to non-specific lesions of the pulmonary tissue and cause the development of toxic effects of oxygen.

Having analyzed the indexes of $\mathrm{FiO}_{2}$ and the level of $\mathrm{NO}$ metabolites, we obtained the following data: in newborns of the I group $\mathrm{FiO}_{2}$ was $0.60 \pm 0.040$, among the newborns of the II group - $\mathrm{FiO}_{2}$ was $0.38 \pm 0.01$ and in the III group - $\mathrm{FiO}_{2}$ was $0.21 \pm 0.01$. The highest level of $\mathrm{NO}$ metabolites has been registered among newborns of the I group and the lowest - among newborns of the II group. This shows that with an increase in the severity of respiratory insufficiency, the activity of nitrosative processes with excessive accumulation of NO metabolites in pulmonary expiratory cells is compensatory. However, an increase in NO metabolites creates a greater risk of developing oxidative degradation processes in the lung tissue due to the formation of peroxynitrite - a potent oxidant that can damage the alveolar epithelium and pulmonary surfactant. 
In order to analyze the obtained results regarding the influence of NO metabolites on the processes of activation of the prooxidant system, we conducted a multiple regression analysis (Table 2, 3)

\begin{tabular}{|c|c|c|c|c|c|c|}
\hline Figure & $\beta$-coefficient & $\begin{array}{c}\text { Standard } \\
\text { error } \beta\end{array}$ & B & $\begin{array}{c}\text { Standard } \\
\text { error B }\end{array}$ & T-statistics & $\begin{array}{c}\text { Significance } \\
\text { Level }\end{array}$ \\
\hline & \multicolumn{6}{|c|}{ I group } \\
\hline NO & 0.613013 & 0.138727 & $\mathbf{0 . 0 2 9 2 3 3}$ & 0.006615 & 4.418839 & 0.001674 \\
\hline PCNC & 1.608838 & 0.265237 & 0.984668 & 0.162335 & 6.065657 & 0.02612 \\
\hline PCAC & -0.64055 & 0.177986 & -0.09424 & 0.026187 & -3.59888 & 0.069281 \\
\hline $\mathrm{FiO}_{2}$ & $\begin{array}{l}\mathbf{0 . 7 2 8 3 9 9} \\
\end{array}$ & 0.163615 & 1.499851 & $\begin{array}{l}0.3369 \\
\end{array}$ & 4.451917 & 0.046932 \\
\hline \multicolumn{7}{|c|}{ II group } \\
\hline $\mathrm{NO}$ & 0.435872 & 0.186766 & 0.064611 & 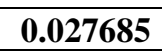 & \begin{tabular}{|l|l|}
2.3337899 \\
\end{tabular} & \begin{tabular}{|l|l|}
0.028708 \\
\end{tabular} \\
\hline$\overline{\mathrm{PCNC}}$ & 0.137745 & 0.20688 & 0.834677 & 1.253613 & 0.665818 & 0.512151 \\
\hline PCAC & -0.20817 & 0.263174 & -0.00666 & 0.008417 & -0.79102 & 0.437016 \\
\hline $\mathrm{FiO}_{2}$ & 0.466208 & 0.27061 & 0.195032 & 0.113206 & 1.722804 & 0.098345 \\
\hline \multicolumn{7}{|c|}{ III group } \\
\hline $\mathrm{NO}$ & -0.03651 & 0.265843 & -0.0326 & 0.237352 & -0.13733 & 0.893794 \\
\hline PCNC & 1.300929 & 0.425505 & 0.758652 & 0.248138 & 3.057375 & 0.013629 \\
\hline PCAC & -0.55873 & 0.409813 & -0.01554 & 0.011397 & -1.36338 & 0.20589 \\
\hline $\mathrm{FiO}_{2}$ & -0.12901 & 0.271296 & -5.00276 & 10.52036 & -0.47553 & 0.645738 \\
\hline
\end{tabular}

PCNC - protein carbonyls of neutral character; PCAC - protein carbonyls of alkali character

Source: Author

The obtained results indicate that NO (active oxidant) directly affects the increase in activity of processes of proteins and lipids peroxidation by increasing of the total oxidation potential. This is proved by the reliable coefficients of multiple correlation among children of group I ( $R=0.99$, $\mathrm{R}^{2}=0.993$, normalized $\left.\mathrm{R}^{2}=0.978\right)$ and group II $\left(\mathrm{R}=0.79 ; \mathrm{R}^{2}=0.632\right.$, normalized $\left.\mathrm{R}^{2}=0.552\right)$. This results in the possibility to substantiate that the obtained linear model of protein peroxidation activation is adequate for newborns of the groups I and II ( $\mathrm{F}=7.90 ; \mathrm{p}<0.00019 ; \mathrm{F}=63.24 ; \mathrm{p}<0.015$, respectively), it points to the possibility of the creation of reliable prognosis.

The adequacy of the connection in the multiple linear regression equations of the activation of lipid peroxidation was also verified by Fisher's $\mathrm{F}$ criterion, which indicates a sufficiently high quality of the received pattern, namely: I group $-\mathrm{F}=22.921, \mathrm{p}<0.024\left(\mathrm{R}=0.99 ; \mathrm{R}^{2}=0.982\right.$, normalized $\left.\mathrm{R}^{2}=0.939\right)$; group II - $\mathrm{F}=4.79, \mathrm{p}<0.020\left(\mathrm{R}=0.85, \mathrm{R}^{2}=0.772\right.$, normalized $\left.\mathrm{R}^{2}=0.575\right)$.

The results of the investigation indicate that the dependence observed between the level of NO metabolites, the concentration of oxygen in the mixture, which is carried out by respiratory support, and the activity of the processes of peroxidation of proteins and lipids is not accidental and is a real fact.

As it is shown in Figure 1, in groups I and II the level of nitrogen monoxide is higher compared to the III group. This may be due to compensatory reaction of the endothelial pulmonary system, which is aimed at the restoration of blood flow under the "crisis of pulmonary microcirculation". However, excessive formation of nitrogen monoxide is a risk factor for the initiation of oxidative stress processes.

Thus, according to the results of our research, it can be stated that excessive endogenous NO formation under conditions of high concentrations of oxygen subsidization results in an increase in the activity of peroxidation processes, which in the future provokes the development of oxidative degradation of protein and lipid molecules in the structures of the aero-hemic space.

Conclusion. Nitrogen monoxide is one of the factors of activation of free radical oxidation at the level of the alveolar-capillary space among newborns with respiratory distress. In intensive care for newborns with severe respiratory failure, the use of excessive oxygen concentrations should be avoided, as on the background of increased endogenous NO formation, there is a greater risk factor for the toxic effect of oxygen on the biological structures due to the increased formation of active forms of oxygen with the development of oxidative stress. 


\section{References}

Zubrihina G.N., Gorozhanskaya E.G., Dobrovolskaya M.M. et al. (2007) Nitric oxide and superoxide dismutase in intensive chemotherapy of oncologic patients. Bulletin of Intensive Care. 2. 14-18. (in Ukrainian)

Flanagan R.J., Braithwaite R.A., Braun S. (1997) Fundamentals of analytical toxicology. WHO, Geneva. 7.

Frye A.D. (2005) Acute lung injury and acute respiratory distress syndrome in the pediatric patient. Crit. Care Nurs. Clin. North Am. 17 (4). 311-318.

Junichi F., Iuchi Y., Okada F. (2005) Fundamental roles of reactive oxygen species and protective mechanisms in the female reproductive system. Reprod. Biol. Endocrinol. 3. 43.

Yaschenko Yu.B., Buriak O.G. (2010) Unresolved issues of the use of nitric oxide as a diagnostic and therapeutic agent in neonatology. Modern pediatrics. 4 (32). 97-100. (in Russian)

Buriak O.G., Yaschenko Yu.B. (2010) Application of exhaled breath condensate as a biological environment for immunobiochemical studies. Bulletin of Social Hygiene and Health Care Organizations. 2. 35-38. (in Russian)

Buriak O.G. Influence of negative factors on development of respiratory insufficiency of pulmonary genesis on the background of nitrosistic stress in newborns in critical conditions. Clinical and Experimental Pathology. 10 (2). 6-8. (in Russian) 